\title{
La teoría del olvido en san Agustín y Freud
}

El simple enunciado de estas consideraciones puede levantar más de una sospecha acerca de su rigurosidad ${ }^{1}$. Por eso es necesario anticipar, antes de nada, que no se pretende afirmar la identidad de pensamiento entre San Agustín y Freud. Esto sería, sin más, un empeño absurdo. Solamente se intenta destacar que uno de los conceptos más fructíferos de la doctrina agustiniana sobre la memoria ha revivido en la psicología freudiana con tal intensidad que pasó a ser uno de los puntos básicos del psicoanálisis. Es curioso y sorprendente observar cómo, a lo largo de la historia, muchas ideas conquistadas por el hombre han perdurado bajo mil formas distintas, bajo los aspectos más insólitos, y han sido utilizadas de modos totalmente diferentes. En realidad, podemos afirmar que un conocimiento, un principio es válido,

1. La teoria agustiniana del "inconsciente" ha sido varias veces presentada. Gilson, por ejemplo, escribe: "le terme de mémoire signifie beaucoup plus que ce que désigne son acception psychologique mođerne: le souvenir du passé. Il s'applique, chez saint Augustin, à tout ce qui est présent à l'âme (présence qui s'atteste par une action efficace) sans être explicitement connu ni perçu. Les seuls termes psychologiques modernes qui soient équivalents à la memoria augustinienne sont ceux d'inconscient ou de subconscient, pourvu qu'on les élargisse eux-mêmes, comme on verra plus loin, jusqu'à inclure, outre la présence à l'âme de ses propres états non actuellement perçus, la préserice métaphysique à l'âme d'une réalité distincte d'elle, et transcendante, telle que Dieu" (Introduction a l'étude de saint Augustin, Paris, Vrin. 1949, p. 135, not. 2).- Vid: Moran, J.- La teoría del conocimiento en San Agustín (Valladodid, Archivo Agus tiniano, 1961). HaRTMan, R. S.- The Epistemology of the "A priori" (A propósito del artículo "On the Distinction between the Analytic and the Sinthetic" de Wild y Cobitz); Philosophy and Phenomenolodical Research. 9 (1949), 731-736. CAYRE.- L' intuition intellectuelle dans la philosophie de saint Augustin: L'Année Théologique 8 (1947) 468-471. Plinval, G. de. La dialectique d'Augustin: Recherches et Débats, 8 (1954), 219-238. MaccagnoLo, E. Appunti per una interpretazione di Sant'Agostino: Sophia, 23 (1955), 223-232. SAL, O.F.S. Criteriología y conocimiento natural: Ortodoxia. 1617 (1947), 156-191. 
históricamente, en la medida en que continúa dando frutos, aunque estos frutos no sean siempre los mismos. Es más, su capacidad fructificadora se mide por su capacidad diversificadora.

Los puntos en que San Agustín y Freud coinciden casi literalmente son: a) La defensa de una latencia psíquica, b) la fundamentación de esta latencia, en parte, sólo en parte, en una teoría del olvido, considerándolo como un ocultamiento, no como una desaparición total del campo psíquico.

Sabido es que, para Freud, lo latente, aquello que no está expresado en la conciencia, implica la existencia del inconsciente. $Y$ el inconsciente constituye una de las tesis fundamentales de toda su doctrina. La confirmación textual en la que se relacionen recuerdo e inconsciente es fácil encontrarla: "Podemos aducir -escribe Freuden apoyo de la existencia de un estado psíquico inconsciente, el hecho de que la conciencia sólo integra en un momento dado un limitado contenido, de manera que la mayor parte de aquello que denominamos conocimiento consciente tiene que hallarse de todos modos, durante largos períodos de tiempo, en estado de latencia; esto es, en un estado de inconsciencia psíquica. La negación de lo inconsciente resulta incomprensible en cuanto volvemos la vista a todos nuestros recuerdos latentes. Se nos opondrá aquí la objeción de que estos recuerdos latentes no pueden ser considerados como psíquicos, sino que corresponden a restos de procesos somáticos, de los cuales puede volver a surgir lo psíquico. No es difícil argüir a esta objeción que el recuerdo latente es, por lo contrario, un indudable residuo de un proceso psiquico. Pero es aún más importante darse cuenta de que la objeción discutida reposa en una asimilación de lo consciente a lo psíquico. Y esta asimilación es o una repetición de principio, que no deja lugar a la interrogación de si todo lo psíquico tiene también que ser consciente, o una pura convención. En este último caso, resulta, como toda convención, irrebatible, y sólo nos preguntamos si resulta en realidad tan útil y adecuada que hayamos de agregarnos a ella. Pero podemos afirmar que la equiparación de lo psíquico con lo consciente es por completo inadecuada. Destruye las continuidades psíquicas, nos sume en las insolubles dificultades del paralelismo psicofísico, sucumbe al reproche de exagerar sin fundamento alguno la misión de la conciencia y nos obliga a abandonar prematuramente el terreno de la investigación psicológica, sin ofrecernos compensación alguna en otros secto- 
res)..${ }^{2}$. Es decir, Freud, considera la conciencia como un estado eminentemente transitorio. Una percepción, por ejemplo, tiene una duración limitada en la conciencia. Las representaciones son conscientes en un momento dado, pero dejan de serlo en el inmediatamente ulterior, aunque puedan volver a serlo en determinadas condiciones. $\mathrm{Pe}$ ro, entre la primera expresión en la conciencia y su posterior evocación, no han desaparecido totalmentes del psiquismo. Hemos de afirmar que estaban latentes, significando con ello que eran en todo momento del tal intervalo capaces de conciencia ${ }^{3}$. Los términos (inconsciente», "latente», "capaz de conciencia), se usan en este caso indistintamente ${ }^{4}$, aunque el término (inconsciente) tenga también otros sentidos en función de la represión. Lo inconsciente latente será propiamente lo preconsciente ${ }^{5}$. Cuando, en consecuencia, hable Freud del olvido, de los recuerdos de la memoria, de las omisiones, etc., recurrirá al supuesto de lo latente para dar razón de una multitud de experiencias. Así, al comprobar que muchos recuerdos de la infancia son aparentemente nimios, insignificantes, como el del individuo que refiere el haber tronchado una ramita de un árbol durante un paseo considerándolo su primer recuerdo de la infancia, Freud descubre que, en realidad, lo que sucede es que de la escena se evocan únicamente algunos elementos, permaneciendo otros en la retaguardia de la conciencia. Estos últimos han desaparecido para el sujeto y no puede hacérselos presentes. Pero los elementos que no aparecen en el recuerdo sólo han sido omitidos. "En el tratamiento psicoanalítico —confirma Freud - me ha sido posible descubrir muchas veces los fragmentos restantes del suceso infantil, demostrando así que la impresión, de la cual subsistía tan sólo un torso en la memoria, confirmaba, una vez completada, la hipótesis de la conservación mnémica de lo importante) ${ }^{\circ}$. Incluso estos elementos ocultos pueden emerger a través de un («recuerdo encubridor), que no debe su valor mnémico al propio contenido, sino a la relación del mismo con otro contenido reprimido" ? De ahí la posibilidad de que todos (nuestros recuerdos infantiles conscientes nos muestren los primeros años de nuestra existencia, no como fueron, sino como nos parecieron al evocarlos luego, en épocas poste-

2. Freud, S., Obras completas. Trad. esp. Luis López-Ballesteros, (Madrid, Ed. Biblioteca Nueva, 1948), vol. I, p. 1064.
3. Id. p. 1213.
4. Id. Id.
5. Id. p. 1214.
6. Id. p. 159.
7. Id. p. 165. 
riores) ${ }^{8}$. Y al análisis de estas transposiciones, lagunas, omisiones, latencias, y su significado en la vida del individuo dedica Freud gran parte de su obra. En el tratado: Psicopatología de la vida cotidiana ${ }^{9}$ analiza el olvido de nombres propios, de palabras extranjeras, de nombres y de series de palabras, de equivocaciones orales, de equivocaciones en la lectura y en la escritura, etc., etc. Todo ello se mantiene dentro de una misma línea doctrinal. Esto es, supone la existencia en el psiquismo de una multitud de contenidos que actúan en nuestras vidas, pero que permanecen ocultos, traspuestos a la vigilancia de la conciencia. El olvido, por lo tanto, no es una desaparición total de lo olvidado del campo psíquico, sino solamente una retirada de la conciencia, como un hundimiento sobre el que crecen nuevos datos, nuevas relaciones, nuevas vivencias, impidiendo, obstaculizando, bloqueando o transformando su evocación y su expresión posterior.

Si ahora nos fijamos en San Agustín y tratamos de seguirle desde los primeros análisis que hace de la memoria sensible, nos encontramos con que comienza haciendo destacar desde el primer momento en la actuación de la memoria una duplicidad paradójica, que determina inmediatamente su dinámica interna. "Recordar algo ${ }^{10}$ es "representar) conscientemente lo que con anterioridad había sido vivenciado por el sujeto. El recuerdo es un acto de la memoria. En cuanto tal, solamente se produce en la medida en que evoco, traigo a la plataforma de mi conciencia presente, una cierta (representación». Así, al recordar $\mathrm{mi}$ infancia, me la voy haciendo presente en sus distintas etapas, en sus distintas formas y momentos. También me hago presentes los lugares por donde transcurrió y las personas con quienes fue paulatinamente desarrollándose. Hay, desde luego, múltiples situaciones de las que ahora no soy capaz de reproducir ni el detalle más insignificante. Permanecen en una oscuridad total. Están ocultas en las zonas más profundas del espíritu. Para que se transformen en recuerdo expreso he de volverlas a la luz del aquí y ahora en que vivo, a la luz de la actualidad. Pero, a su vez, esta acción que consiste en traer algo de nuevo ante mí, no sólo es una actividad que me pertenece: "Porque no exploramos ahora las regiones del cielo, ni medimos las distancias de los astros, ni buscamos los cimientos de la tierra: soy

8. Id. p. 167.

9. Id. p. 635 .

10. Rodriguez Neira, T. Sentido gnoseológico de la memoria en San Agustín: Estudio Agustiniano, VI (1971), p. 372ss. 
yo el que recuerdo, yo el alma) "11, sino que además, lo que recuerdo, lo evocado, corresponde a mi campo vital, al radio de mi propia vida. Así distingue San Agustín este peculiar fenómeno psíquico de todos aquellos en los que, como en el imaginar, interviene también una actividad representativa.

Por otra parte, la evocación implica ausencia. No recuerdo lo que en este instante veo, toco y siento. Lo recordaré cuando ya no 10 vea, ni toque, ni sienta. Es decir, cuando se haya ocultado en el transfondo del alma. Pero esta ausencia no ha de ser absoluta. (La ausencia se refiere a una pérdida de la conciencia). Caso de ser absoluta, ya nunca sería posible el recuerdo. El recuerdo es, en consecuencia, para San Agustín, una ausencia (presente) de una presencia (ausente).

Esta propiedad es fácil de verificar: Supongamos que alguien quiere traernos a la memoria algo de lo que nos hemos olvidado. Nos irá proponiendo diversas cosas para intentar sugerirnos lo que no somos capaces de evocar. Sin embargo no acabamos de recordar lo que deseamos. Y nos damos cuenta de que aquello que intentamos recordar no es exactamente lo mismo que nos sugieren. No se trata, por lo tanto, de un olvido completo. El mismo discernimiento entre lo buscado y lo propuesto forma parte de un cierto recuerdo ${ }^{12}$, es decir, de una cierta presencia, de una presencia oculta, escondida, ((ausente), que se hará "presente» al ser evocada.

Y lo mismo sucede en el reconocimiento del recuerdo. Es lo que nos ("ocurre, escribe San Agustín, cuando vemos alguna cosa, recordamos ciertamente que la hemos visto alguna vez y aseguramos qu la conocemos; nos esforzamos por recordar dónde, cuándo, cómo y con quién ha llegado a nuestra noticia. ¿Se trata de una persona? Buscamos también dónde la hemos conocido; y cuando ella nos lo recuerda, de repente, todo nos vuelve a la memoria como una luz, y sin ningún esfuerzo todo lo reproducimos) ${ }^{13}$.

Pero quizá haya algún aspecto, puede pensarse, en el que no se cumpla esta ley. Trátase, pongamos por caso, de la presencia que implicaría el recuerdo del olvido. Porque también me acuerdo de haberme olvidado muchas veces y en múltiples ocasiones. Mas, si el olvido es privación de memoria, ¿`“cómo está presente en la memoria para

11. Conf. X, 16, 25 .

12. Solil. II, 20,34 .

13. Id. Id. 
acordarme de él, siendo así que estando presente no puedo recordarlo. No obstante, si es cierto que lo que recordamos lo retenemos en la memoria, y que, si no recordásemos el olvido, de ningún modo podríamos, al oir su nombre, saber lo que por él se significa, síguese que la memoria retiene el olvido. Luego está presente para que no olvidemos la cosa que olvidamos cuando se presenta) ${ }^{14}$.

Acaso se diga que lo que retenemos es la imagen del olvido, no el olvido mismo, a la manera como retenemos las imágenes de las cosas que han impresionado nuestros sentidos, y por medio de ellas las recordamos. Pero en este caso volvemos a la misma dificultad, ya que, para que una imagen se grabe, es preciso que previamente esté presente la cosa misma de la que obtenemos la imagen. $Y$, si el olvido está presente en el recuerdo de su imagen, es preciso que con anterioridad el olvido haya estado por sí mismo presente. "Mas cuando estaba presente, ¿cómo esculpía en la memoria su imagen, siendo así que el olvido borra con su presencia lo ya delineado? $\mathrm{Y}$, sin embargo, de cualquier modo que ello sea -aunque este modo sea incomprensible e inefable-, yo estoy cierto que recuerdo el olvido mismo con que se sepulta lo que recordamos) ${ }^{15}$. Luego, no nos queda otra solución, si admitimos que se da un recuerdo del olvido, que suponer su presencia en el sujeto para que efectivamente pueda ser recordado.

Observando la cuestión desde otra perspectiva puede hacérsenos comprensible la solución del problema. La verdad es que todo recuerdo directamente procurado, intentado, es una búsqueda. Y esta búsqueda llega a su cumplimiento cuando conseguimos la representación consciente de lo buscado. Esta representación consciente conseguida implica la presencia previa, anterior a la conciencia, de lo buscado. Gracias a esta presencia previa, por otra parte, somos capaces de identificar la realidad concreta como aquello que responde adecuadamente a las exigencias subjetivas en este campo. Por eso, la desaparición en el olvido no puede ser una desaparición total. Y el olvido mismo no es un borrarse absoluto, sino más bien un ocultarse. "No se puede decir, concluye San Agustín, que nos olvidamos totalmente, puesto que nos acordamos al menos de habernos olvidado y de ningún modo podríamos buscar lo perdido que absolutamente hemos olvidados ${ }^{16}$.

14. Conf. X, 16,24.

15. Conf. X, 16,25.

16. Conf. $\mathrm{X}, 19,28$. 
Este aspecto de la memoria abre precisamente la dimensión del inconsciente y su influencia en el desarrollo posterior de la personalidad. Si el olvido no significa desaparición total, y, sin embargo, representa una retirada de la conciencia presente, es que existe una forma de conservación previa a la conciencia, existe el inconsciente, o lo latente, lo que está en nosotros aunque no nos percatemos de ello. San Agustín habrá expresado de este modo una idea afortunada que alcanzará su pleno desarrollo en la psicología de hoy. "Sería imposible, se ha escrito, tener presente y abarcar en cada momento, en claras representaciones, el conjunto de nuestro pasado anímico, de todo nuestro saber, de todas nuestras experiencias, vivencias afectivas y valores a que hemos aspirado alguna vez. Es manifiestamente una forma de economía el hecho de que nuestro vivenciar esté organizado de tal modo que lo que hemos sentido, pensado, aprendido, querido y experimentado desde nuestra primera infancia se hunda en una región profunda del inconsciente y sólo una parte mínima de nuestro pasado sea consciente, esto es, se halle presente en las representaciones del recuerdon" ${ }^{17}$.

La tesis agustiniana tiene, desde luego, una extensión mayor que la que aquí se le da a la memoria en cuanto puramente experiencial. La memoria en San Agustín mantiene esta misma naturaleza aun en aquellas funciones que transcienden toda experiencia. Se refiere no sólo al pasado como pretérito, sino también al presente en tanto que vivenciado o susceptible de ser vivenciado. Comprende, de este modo, incluso aquello que por naturaleza tiene que estar en cierta manera presente aunque no haya sido todavía experimentado. $\mathrm{Y}$ esta es precisamente la razón de su diferencia con la teoría platónica.

Los términos con que Platón describe en el Banquete la presencia del objeto amado son muy parecidos a los que utiliza San Agustín para expresar la presencia de ese mismo objeto y la presencia del recuerdo. El amor, para Platón, se encuentra en el término medio entre la sabiduría y la ignorancia. No es sabiduría total, ni es ignorancia total. Y esta ignorancia, que no es un no saber radical, adelanta aquella sabiduría con cuyo logro conseguirá el sujeto satisfacer su necesidad. $\mathrm{Si}$ añadimos la teoría general del conocimiento como recuerdo, fácil será ir determinando el proceso ascensional del hombre, de modo que le sea posible acceder al ideal, a la Idea. A pesar de todo, Platón ne-

17. LERSCH, PH. La estructura de la personalidad. (Barcelona, 1966) p. 29. 
cesitará recurrir, para explicar el punto de partida inicial, a una experiencia previa, a una vida anterior, supuesto que no tiene cabida en la doctrina agustiniana. Para San Agustín el recuerdo como fenómeno empírico implica ya una latencia. Pero, además, admite otras presencias latentes, ocultas, que son deducidas de un análisis de la naturaleza humana y que constituyen un elemento integrante de esa misma naturaleza.

Se podría pensar que la teoría del olvido y la idea de lo latente, de lo implícito, del inconsciente es una idea esporádica dentro del pensamiento agustiniano. Es necesario afirmar, sin embargo, que de ella depende su teología, su moral y su gnoseología. Bástenos desarrollar, para confirmarlo, algún aspecto de la autopresencia del alma con el fin de insinuar la amplitud de la problemática en la que, dentro de este terreno, se mueve San Agustín.

Comenzaremos por la distinción entre conocimientos cadventicios) y conocimientos (naturales", tal como la plantea el Obispo de Hipona.

Llámanse "adventicios» todos aquellos conocimientos que tienen su orden en el tiempo. Así, los conocimientos históricos, ya se trate de acontecimientos, de hechos, o de dichos pasados y que llegan hasta nosotros por ciertos vestigios en los que se conserva la huella de su paso, ya se trate de lo que sucede y es retenido en la memoria. De la misma índole son todos aquellos conocimientos que de alguna manera comienzan a existir en un momento determinado, bien sea por la enseñanza, bien por reflexión propia. También se incluye entre los "adventicios) el conocimiento sensible en general para el que se necesita la presencia del objeto o de su imagen, y todo aquello que de una manera u otra a él se reduzca.

Conocimiento (natural», sin embargo, es el que antecede a todo desarrollo y progreso en el tiempo, y nace con el hombre mismo, con la misma existencia. El objeto de este conocimiento no se percibe fue$\mathrm{ra}$, sino dentro. $\mathrm{Ni}$ el recuerdo, ni la comprensión en este caso se refieren a imágenes de realidades externas, sino a lo que se descubre en la intimidad ${ }^{18}$. Este conocimiento es previo a toda expresión en la conciencia, es inconsciente, aunque puede, naturalmente, manifestarse en la conciencia.

18. De Trinit. XIV, 8,11. 

rísticas?

¿Se da efectivamente un conocimiento que revista estas caracte-

Pensemos en el conocimiento que el alma tiene de sí misma. (Nada tan conocido del alma, escribe San Agustín, como aquello que siempre tiene presente, y nada tan presente al alma como el alma misma) ${ }^{19}$. El alma humana siempre se recuerda, siempre se conoce y siempre se ama ${ }^{20}$.

La presencia del alma a sí misma, el autoconocimiento, es algo que pertenece a la misma naturaleza del alma. Cuando piensa en sí, retorna a su presencia mediante un acto inmaterial y reflejo. Cuando no se piensa, no podemos decir en verdad que informe la mirada de su pensamiento, pero se conoce como si ella fuera para sí su memoria. Es como un hombre que conoce muchas ciencias. Sus conocimientos están en su memoria. Sólo cuando reflexiona, cuando piensa en ellos, vuelven a la presencia consciente de su mente, lo demás permanece oculto mediante ciertas (escondidas noticias) que se conservan en la facultad de la memoria. Y el conocimiento que surge en la mente cuando el alma se comprende y se ve, no surge como si antes fuera para sí una desconocida - nec ita sane gignit istam notitiam suam mens, quando cogtando intellectam se conspicit, tanquam sibi ante incognita fuerit-, sino que se conocía como se conocen las cosas que se conservan en la memoria, aunque no se piense en ellas ${ }^{21}$. Pódemos decir sin contradicción que el alma humana se conoce antes de conocerse, de pensarse.

Tal vez se crea que el alma sólo se recuerda, sin conocerse, porque la noticia de una cosa cualquiera impresa en la mente, cuando en ella no se piensa, pertenece exclusivamente a la memoria. Pero sucede aquí de una manera parecida a lo que ocurre con el hombre entendido en música que, en un momento dado, se ocupa en resolver problemas de matemáticas. ¿Diremos acaso que, cuando piensa en las matemáticas, desconoce la música en la que es precisamente una autoridad? "Esto nos hace comprender la existencia en lo profundo del alma de ciertas noticias que salen a la superficie y se ponen en presencia del alma misma cuando en ellas se piensa. Entonces descubre el alma su conocimiento, su recuerdo y su amor, incluso cuando no se pensaba al pensar en otras cosas)s ${ }^{22}$.

19. De Trinit. XIV, 5,7.

20. De Trint. XIV, 7,9.

21. De Trinit. XIV, 6,8.

22. De Trinit. XIV, 7,9. 
En los conocimientos (adventicios), ciertos cognoscibles preceden en el tiempo al conocimiento. Así sucede con las realidades sensibles existentes antes de ser conocidas, o los conocimientos de la historia. Otros, existen al mismo tiempo, como ocurre con la audición y el sonido. Y una vez realizado el conocimiento, el recuerdo latente en la memoria es anterior a las sucesivas representaciones mnémicas. No acontece así con el alma. Porque el alma no es para sí adventicia. Desde el mismo momento en que comenzó a existir, nunca dejó de recordarse, conocerse y amarse -cum profecto ex quo esse coepit, nunquam sui meminisse, nunquam se intelligere, nunquam se amare destiterit ${ }^{23}$.

San Agustín se da perfecta cuenta de que está introduciendo un nuevo concepto de memoria, una memoria de las cosas presentes mediante la cual el alma, por ejemplo, está siempre en presencia de sí. Una memoria que ya no es simplemente una memoria del pasado. "Asi como con respecto a las cosas pretéritas se llama memoria a la facultad que las retiene y las recuerda, así, con relación al presente, cual lo está el alma para sí misma, se puede llamar sin escrúpulo memoria a la facultad de estar presente a sí misma, para que pueda por su propio pensamiento conocerse y puedan así las dos realidades ser por el amor unidas ${ }^{24}$.

Una presencia en la memoria de parecida índole, un conocimiento natural, inconsciente, por tanto, es el que tenemos también de los primeros principios, de la Verdad, de Dios ${ }^{\frac{15}{25}}$.

El concepto de memoria se extiende, en consecuencia, según el pensamiento agustiniano, a todo lo que está presente al alma de una manera inconsciente o intemporal. Tratándose de la memoria sensible, ya lo hemos visto, también se da en ella una presencia inconsciente de un número indefinido de conocimientos. Es la característica fundamental de toda memoria. Pero, en la memoria sensible, esa presencia es temporal. Es presencia de objetos: imágenes, recuerdos, conceptos recibidos o formados en el tiempo. Están presentes al alma en la memoria, es verdad, pero no la han estado siempre. Han comenzado a estar en un tiempo determinado, aunque el alma misma no haya tenido conciencia de su incorporación.

Las presencias de lo que hemos llamado conocimiento natural son

23. De Trinit. XIV, 10,13 .

24. De Trinit. XIV, 11,14.

25. De Trinit. XIV, 13,17. 
de siempre, transcienden el tiempo. Son coexistentes con el alma. Desde que el alma es alma las tiene presentes a sí misma... San Agustín define estas presencias con un nombre técnico: Nociones. Y consisten en un conocimiento natural, a priori, en un recuerdo fuera del tiempo de ciertas realidades...

Es realmente sorprendente observar cómo una misma idea ha servido a Freud para elaborar una metapsicología, una psicología profunda, en busca de los procesos etiológicos que expliquen el deterioro mental, los transtornos psíquicos; a San Agustín, para fundamentar la teología, para descubrir la raíz del conocimiento humano, para acceder a la fuente de lo religioso y transcendente. El psicoanálisis sin el inconsciente carece de base. Las exaltaciones místicas de San Agustín sin la presencia oculta de la verdad en el interior, sin la presencia de los primeros principios en las profundidades oscuras y casi impenetrables de la memoria, sin una latencia de lo absoluto, que bien puede quedar soterrado en esa pura latencia, las expresiones místicas de San Agustín, sin esta hipótesis, serían en gran parte charlatanería y retórica. Tal vez no nos sorprenda tanto esta coincidencia, tal vez no nos llame tanto la atención el hecho de que San Agustín sorprenda una luz secreta en las reconditeces del espíritu, si podemos ver que una rama del psicoanálisis ha llegado a una conclusión parecida. Para Jung, por ejemplo, el conocimiento de sí, del inconsciente, de lo latente, conduce a la fundamentación de la experiencia religiosa: "A la cuestión de la experiencia religiosa sólo hay respuesta positiva si el hombre está dispuesto a satisfacer el requisito de riguroso autoexamen y autoconocimiento. Si cumple este propósito, que está al alcance de su voluntad, además de descubrir muchas verdades sobre sí mismo ganará una ventaja psicológica: logrará poner seria atención y tomar un vivo interés en sí mismo. Con lo que, en cierto modo, firmará ante sí propio una declaración de la dignidad humana y dará al menos el primer paso hacia la aproximación al fundamento de su conciencia, el inconsciente que es la fuente de experiencia religiosa que por lo pronto se nos ofrece. Esto no significa en absoluto que el llamado inconsciente sea cuasi idéntico con Dios o tome su lugar; es el medio en el cual, para nosotros, parece originarse la experiencia religiosa» ${ }^{26}$. Y en otra parte de la misma obra señala: "No son normas morales, por muy elevadas que sean, no profesiones de fe, por más que

26. Jung, C. G., Gegenwart und Zukunft. (Zürich 1957). Presente $y$ futuro (Buenos Aires 1963) p. 83. 
ortodoxas, las que constituyen el fundamento de la autonomía y libertad del individuo; es única y exclusivamente la conciencia empirica, esto es, la vivencia inequívoca de una personalísima relación mutua entre el hombre y una instancia extramundana opuesta al (mundo y su razón) ${ }^{27}$.

Desde otras perspectivas y situaciones se ha llegado también al descubrimiento de lo que podríamos designar como dimensión típicamente agustiniana. Bástenos mencionar a Jean $\mathrm{E}$. Charon : «El carácter necesario de la religión se impone como una búsqueda entrañada en la vocación profunda del hombre, una búsqueda de un mejor conocimiento de nuestra realidad interior, una busca de todos los nexos íntimos que relacionan a cada uno de nosotros con ese Ser del cual no somos al mismo tiempo más que una parte, por la representación consciente incompleta que nos hacemos de él, y que es, no obs tante, un Ser enteramene solidario de nosotros mismos por intermedio de ese Yo inconsciente que hace de cada uno de nosotros un punto de convergencia de la totalidad del cosmos) ${ }^{28}$.

En los ocultos campos de la memoria descubre San Agustín las verdaderas raíces de la afirmación religiosa. No se trata de una consecuencia injustificada y caprichosa. Es una tesis rigurosamente formulada y defendida. Nuestra vida apetitiva, la tendencia a la felicidad, a la verdad, al ser, descansan, para San Agustín, en el correlativo objetivo del Bien, de la Verdad, del Ser, impresos en lo más profundo de nuestra naturaleza.

El mundo de los recuerdos latentes es más amplio, más profundo y complejo que el de las expresiones mnémicas. Y el olvido, tanto para San Agustín como para Freud, no significa una desaparición total del campo psíquico. Los enunciados están formulados en términos casi idénticos. La utilización, sin embargo, que de ellos se hace es completamente distinta. En uno, se desarrolla a nivel empírico-psicológico; en otro, metafísico-transcendente. Incluso hemos de afirmar la posibilidad de nuevos e imprevistos manejos que lleven estas mismas tesis a resultados imposibles de anticipar en estos momentos. La historia se nos ofrece como una dilatada tierra de cultivo donde las mismas

27. Id. p. 26.

28. Charon, J.E., De la Physique a L'Homme, (Ginebra, 1964). De la Fisica al hombre, (Madrid 1967) p. 163. 
semillas nos van proporcionando renovadas cosechas que mantienen al hombre despierto ante las múltiples posibilidades que frente a él constantemente se abren y se abrirán.

Teofilo Rodriguez NeIRA Colegio Universitario de León 